\title{
An infertile patient with Y chromosome b1/b3 deletion presenting with congenital bilateral absence of the vas deferens with normal spermatogenesis
}

\author{
Shinnosuke Kuroda', Kimitsugu Usui', Kohei Mori', Kengo Yasuda', Takuo Asai', Hiroyuki Sanjo ', Hiroyuki Yakanaka', \\ Teppei Takeshima', Takashi Kawahara², Haruka Hamanoue ${ }^{3}$, Yoshitake Kato' ${ }^{1}$, Yasuhide Miyoshi' ${ }^{2}$, Hiroji Uemura², \\ Akira Iwasaki' ${ }^{1}$, Yasushi Yumura' ${ }^{1}$ \\ 'Department of Urology, Reproduction Center, Yokohama City University Medical Center, Yokohama; ${ }^{2}$ Department of Urology and Renal \\ Transplantation, Yokohama City University Medical Center, Yokohama; ${ }^{3}$ Department of Genetics, Yokohama City University Hospital, Yokohama, Japan
}

We report the case of a 46-year-old Chinese male patient who visited our clinic complaining of infertility. Semen analysis revealed azoospermia, and azoospermia factor c region partial deletion (b1/b3) was detected using $\mathrm{Y}$ chromosome microdeletion analysis. Testicular sperm extraction was performed after genetic counseling. The bilateral ductus deferens and a portion of the epididymis were absent, whereas the remaining epididymis was expanded. Motile intratesticular spermatozoa were successfully extracted from the seminiferous tubule. On histopathology, nearly complete spermatogenesis was confirmed in almost every seminiferous tubule. To our knowledge, this is the first case report of b1/b3 deletion with a congenital bilateral absence of the vas deferens and almost normal spermatogenesis.

Keywords: Male infertility; Y chromosome microdeletion

\section{Introduction}

Currently, one in six couples experiences an infertility problem during their reproductive lifetime [1]. Male infertility accounts for infertility in approximately $50 \%$ of infertile couples [2,3]. Although there are still many unknown causes of male infertility, chromosomal or genetic abnormalities account for $10 \%$ of disorders in spermatogenetic function [4]. The azoospermia factor (AZF) region of the $Y$ chromosome, which is classically divided into the AZFa, AZFb, and AZFc re-

Received: Dec 6, 2017 · Revised: Jan 15, 2018 · Accepted: Feb 7, 2018

Corresponding author: Shinnosuke Kuroda

Department of Urology, Reproduction Center, Yokohama City University Medical Center, 4-57 Urafune-cho, Minami-ku, Yokohama, Kanagawa, Japan

Tel:+81-045-261-5656 Fax: +81-045-231-1846 E-mail: shinnosuke_1014@yahoo.co.jp

This is an Open Access article distributed under the terms of the Creative Commons Attribution Non-Commercial License (http://creativecommons.org/licenses/by-nc/4.0/) which permits unrestricted non-commercial use, distribution, and reproduction in any medium, provided the original work is properly cited. gions, plays an important role in spermatogenesis, and deletions in this region are known to be associated with spermatogenic failure $[4,5]$. AZF deletion was detected in $10 \%$ of infertile men with azoospermia or severe oligozoospermia in a Japanese population [6], but this frequency varies among population groups. Currently, complete deletion of the AZFc region (b2/b4 deletion) is the most common Y-chromosome deletion, and it has never been identified in normospermic men [7]. However, several types of AZFc partial deletions have been identified, including the $\mathrm{gr} / \mathrm{gr}, \mathrm{b} 2 / \mathrm{b} 3$, and b1/b3 subdeletions [8]. There is no consensus on whether partial AZFc deletions affect spermatogenesis, as some authors reported that these deletions are also found in normozoospermic men, with no significant association demonstrated between the deletions and impaired spermatogenesis $[9,10]$. Among these deletions, $\mathrm{gr} / \mathrm{gr}$ deletion is most commonly detected. This includes deletion of the azoospermia gene families; some authors reported that gr/gr deletion is a signifi- 
cant risk factor for infertility $[8,11,12]$. Other groups, however, reported no association between this deletion and spermatogenic failure [13-15]. In contrast, b1/b3 deletion is rare, and its frequency has varied in previous reports [16-19]. Owing to its low frequency, the effects of b1/b3 deletion on spermatogenesis remain unclear [20]. Herein, we present a case of b1/b3 microdeletion with congenital bilateral absence of the vas deferens (CBAVD).

\section{Case report}

A 46-year-old Chinese man presented to presented to Reproduction Center of Yokohama City University Medical Center complaining of infertility for 10 years with the following characteristics: testis volume of 12 and $15 \mathrm{~mL}$ on the left and right, respectively; not definitively palpable bilateral vas deferens; semen volume of $0.5 \mathrm{~mL}$; azoospermia; normal serum gonadotropin; and luteinizing hormone and follicle-stimulating hormone levels of 9.8 and $10.8 \mathrm{U} / \mathrm{mL}$, respectively. His karyotype was 46,XY. A Y-chromosome microdeletion test showed b1/b3 deletion (AZFc partial deletion). Based on these findings, azoospermia owing to CBAVD or nonobstructive azoospermia due to AZFc partial deletion was suspected. After genetic counseling and obtaining informed consent from the patient and his wife, testicular sperm extraction was performed. The right epididymis body and tail were defective; only the head part was confirmed. The ductus epididymis in the remaining epididymis was expanded, and the vas deferens of both sides was also completely absent. Motile intratesticular spermatozoa were successfully extracted from the seminiferous tubule. On histopathology, spermatogenesis was confirmed,

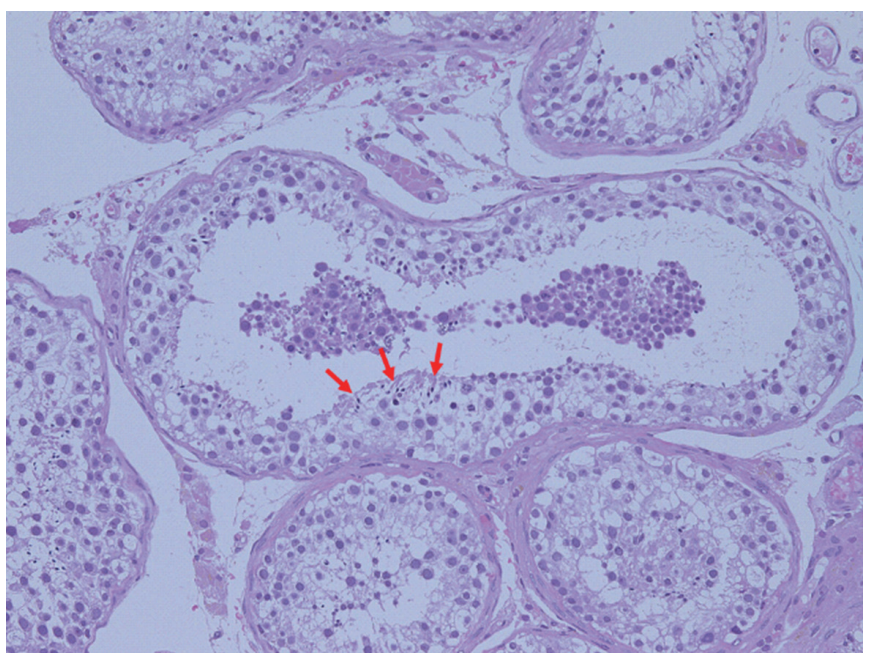

Figure 1. Histopathological findings of the testis $(H \& E, \times 200)$. Spermatogenesis was confirmed, and a few spermatozoa were found (arrows) in almost every seminiferous tubule. The mean Johnsen score count was 8.3. and a few spermatozoa were found in almost every seminiferous tubule. The mean Johnsen score count was 8.3 (Figure 1). The frozen extracted sperm have been used for intracytoplasmic sperm injection (ICSI), which was unsuccessful.

\section{Discussion}

Y-chromosome microdeletions can be found in 10\%-15\% of men with azoospermia or severe oligospermia [2]. AZFa region deletions are associated with Sertoli-cell-only syndrome, which is characterized by the total absence of germ cells; however, AZFa deletions are rare. Complete AZFb region deletions are associated with meiotic arrest, which results in azoospermia, whereas complete AZFc deletions are associated with various phenotypes, including oligozoospermia and azoospermia [21]. Therefore, the American Society for Reproductive Medicine states that Y-chromosome analysis and genetic counseling should be offered to men with nonobstructive azoospermia prior to performing ICSI with their sperm, as there is no possibility to extract sperm through testicular sperm extraction when AZFa or AZFb is deleted [22].

The entire length of the AZFc region spans $3.5 \mathrm{Mb}$, which is removed with the $b 2 / b 4$ deletion. The b1/b3 deletion removes $1.6 \mathrm{Mb}$, which is almost half of the AZFc region. This deletion was defined as the loss of sY1161, sY1191, and sY1291 with the presence of other sequence-tagged sites. Repping et al. [8] demonstrated the mechanism of b1/b3 deletion using fluorescence in situ hybridization; it occurs through homologous recombination, possibly between sister chromatids or within a chromatid. Since its frequency is very low, the effect of this deletion on spermatogenesis remains unknown. To our knowledge, only 36 cases of b1/b3 deletion have been published in the literature $[16,18,19]$. Shahid et al. [18] reported 16 patients with b1/b3 deletion, and stated that a statistically significant difference in the frequency of b1/b3 deletion existed between infertile and fertile men ( $p=0.002)$. However, Ghorbel et al. [23] reported that b1/b3 deletion was found not only in 13 of 261 infertile men (two with azoospermia, six with oligozoospermia, and five with normozoospermia), but also in three fertile men. In other studies, b1/b3 deletion with normozoospermia was not reported. In our case, testicular histology showed normal spermatogenesis. Thus, if the vas deferens had no defect, this case would be the sixth patient with b1/b3 deletion with normozoospermia.

CBAVD accounts for up to $25 \%$ of patients with obstructive azoospermia [24]. CBAVD is sometimes observed as a symptom of cystic fibrosis, a genetic condition causing exocrine gland disorders. Isolated CBAVD is recognized as an autosomal recessive disease that is frequently associated with the cystic fibrosis transmembrane conductance (CFTR) gene [25]. According to a meta-analysis of CBAVD, 78\% 
of patients with CBAVD had at least one CFTR mutation, and the $5 T$ allele and 5T/(TG)12_13 may contribute to the increased risk of CBAVD [26]. In our case, a genetic examination for a CFTR mutation was not performed because we were not able to do a routine check of the CFTR gene in our hospital, and the patient had no past history of chronic bronchitis or sinusitis, which are typical symptoms of cystic fibrosis. In conclusion, we experienced a rare case of an infertile man with $\mathrm{b} 1 / \mathrm{b} 3$ deletion. To our knowledge, this is the first case report of a patient with $\mathrm{b} 1 / \mathrm{b} 3$ deletion with almost normal spermatogenesis and CBAVD. More cases need to be accumulated for further investigation.

\section{Conflict of interest}

No potential conflict of interest relevant to this article was reported.

\section{References}

1. Poongothai J, Gopenath TS, Manonayaki S. Genetics of human male infertility. Singapore Med J 2009;50:336-47.

2. Pryor JL, Kent-First M, Muallem A, Van Bergen AH, Nolten WE, Meisner $\mathrm{L}$, et al. Microdeletions in the $\mathrm{Y}$ chromosome of infertile men. N Engl J Med 1997;336:534-9.

3. Dohle GR, Halley DJ, Van Hemel JO, van den Ouwel AM, Pieters $\mathrm{MH}$, Weber RF, et al. Genetic risk factors in infertile men with severe oligozoospermia and azoospermia. Hum Reprod 2002;17: 13-6.

4. Skaletsky H, Kuroda-Kawaguchi T, Minx PJ, Cordum HS, Hillier L, Brown $L G$, et al. The male-specific region of the human $Y$ chromosome is a mosaic of discrete sequence classes. Nature 2003; 423:825-37.

5. Krausz C, Casamonti E. Spermatogenic failure and the Y chromosome. Hum Genet 2017;136:637-55.

6. Nakashima M, Koh E, Namiki M, Yoshida A. Multiplex sequencetagged site PCR for efficient screening of microdeletions in $Y$ chromosome in infertile males with azoospermia or severe oligozoospermia. Arch Androl 2002;48:351-8.

7. Krausz C, Degl'Innocenti S. Y chromosome and male infertility: update, 2006. Front Biosci 2006;11:3049-61.

8. Repping S, Skaletsky H, Brown L, van Daalen SK, Korver CM, Pyntikova T, et al. Polymorphism for a 1.6-Mb deletion of the human $\mathrm{Y}$ chromosome persists through balance between recurrent mutation and haploid selection. Nat Genet 2003;35:247-51.

9. Carvalho CM, Zuccherato LW, Bastos-Rodrigues L, Santos FR, Pena SD. No association found between $\mathrm{gr} / \mathrm{gr}$ deletions and infertility in Brazilian males. Mol Hum Reprod 2006;12:269-73.

10. Zhang F, Li Z, Wen B, Jiang J, Shao M, Zhao Y, et al. A frequent partial AZFc deletion does not render an increased risk of spermatogenic impairment in East Asians. Ann Hum Genet 2006; 70(Pt 3):304-13.

11. de Llanos M, Ballesca JL, Gazquez C, Margarit E, Oliva R. High frequency of $\mathrm{gr} / \mathrm{gr}$ chromosome $\mathrm{Y}$ deletions in consecutive oligospermic ICSI candidates. Hum Reprod 2005;20:216-20.

12. Ferlin A, Tessari A, Ganz F, Marchina E, Barlati S, Garolla A, et al. Association of partial AZFc region deletions with spermatogenic impairment and male infertility. J Med Genet 2005;42:209-13.

13. Hucklenbroich K, Gromoll J, Heinrich M, Hohoff C, Nieschlag E, Simoni M. Partial deletions in the AZFc region of the $Y$ chromosome occur in men with impaired as well as normal spermatogenesis. Hum Reprod 2005;20:191-7.

14. Machev N, Saut N, Longepied G, Terriou P, Navarro A, Levy N, et al. Sequence family variant loss from the AZFc interval of the human $Y$ chromosome, but not gene copy loss, is strongly associated with male infertility. J Med Genet 2004;41:814-25.

15. Ravel C, Chantot-Bastaraud S, El Houate B, Mandelbaum J, Siffroi JP, McElreavey K. GR/GR deletions within the azoospermia factor $\mathrm{C}$ region on the $Y$ chromosome might not be associated with spermatogenic failure. Fertil Steril 2006;85:229-31.

16. Bansal SK, Jaiswal D, Gupta N, Singh K, Dada R, Sankhwar SN, et al. $\mathrm{Gr} / \mathrm{gr}$ deletions on Y-chromosome correlate with male infertility: an original study, meta-analyses, and trial sequential analyses. Sci Rep 2016;6:19798.

17. Li Q, Song NH, Cao WZ, Shao Q, Xie JJ, Liu C, et al. Relationship between AZFc deletions and testicular histology in infertile south Chinese men with azoospermia and severe oligospermia. Springerplus 2016;5:1805.

18. Shahid M, Dhillon VS, Khalil HS, Sexana A, Husain SA. Associations of $\mathrm{Y}$-chromosome subdeletion $\mathrm{gr} / \mathrm{gr}$ with the prevalence of Y-chromosome haplogroups in infertile patients. Eur J Hum Genet 2011;19:23-9.

19. Shaqalaih AJ, Abu Halima MS, Ashour MJ, Sharif FA. Screening for Y-chromosome microdeletions in a population of infertile males in the Gaza Strip. J Exp Clin Assist Reprod 2009;6:7.

20. Repping S, van Daalen SK, Korver CM, Brown LG, Marszalek JD, Gianotten J, et al. A family of human $Y$ chromosomes has dispersed throughout northern Eurasia despite a 1.8-Mb deletion in the azoospermia factor c region. Genomics 2004;83:1046-52.

21. Mitra A, Dada R, Kumar R, Gupta NP, Kucheria K, Gupta SK. Screening for $\mathrm{Y}$-chromosome microdeletions in infertile Indian males: utility of simplified multiplex PCR. Indian J Med Res 2008;127:124-32.

22. Male Infertility Best Practice Policy Committee of the American Urological Association; Practice Committee of the American Society for Reproductive Medicine. Report on evaluation of the 
azoospermic male. Fertil Steril 2006;86(5 Suppl 1):S210-5.

23. Ghorbel M, Gargouri SB, Zribi N, Abdallah FB, Cherif M, Keskes R, et al. Partial microdeletions in the $Y$-chromosome AZFC region are not a significant risk factor for spermatogenic impairment in Tunisian infertile men. Genet Test Mol Biomarkers 2012;16:7759.

24. Radpour R, Gourabi H, Dizaj AV, Holzgreve W, Zhong XY. Genetic investigations of CFTR mutations in congenital absence of vas deferens, uterus, and vagina as a cause of infertility. J Androl
2008;29:506-13.

25. Bombieri C, Claustres M, De Boeck K, Derichs N, Dodge J, Girodon $\mathrm{E}$, et al. Recommendations for the classification of diseases as CFTR-related disorders. J Cyst Fibros 2011;10 Suppl 2:S86102.

26. Yu J, Chen Z, Ni Y, Li Z. CFTR mutations in men with congenital bilateral absence of the vas deferens (CBAVD): a systemic review and meta-analysis. Hum Reprod 2012;27:25-35. 